\title{
Monitoring the Formation and Reactivity of Organometallic Alkane and Fluoroalkane Complexes with Silanes and Xe Using Time-resolved XAFS
}

Stuart A. Bartlett ${ }^{1,2,3}$, Nicholas A. Besley, ${ }^{4}$ Andrew J. Dent, ${ }^{5}$ Sofia Diaz-Moreno, ${ }^{5}$ John Evans, ${ }^{1,5,6}$, Michelle L. Hamilton ${ }^{1,4}$, Magnus W. D. Hanson-Heine, ${ }^{4}$ Raphael Horvath, ${ }^{4}$ Valentina Manici, ${ }^{1,4}$ XueZhong Sun, ${ }^{4}$ Michael Towrie, ${ }^{1,7}$ Lingjun Wu, ${ }^{4}$ Xiaoyi Zhang ${ }^{8}$ and Michael W. George, ${ }^{1,4,9}$

${ }^{1}$ DySS, Research Complex at Harwell, Rutherford Appleton Laboratory, Didcot, OX11 OFA, UK ${ }^{2}$ School of Chemistry, The University of Sydney, Eastern Ave, Sydney NSW 2006, Australia ${ }^{3}$ Department of Chemistry, University of Bath, Claverton Down, Bath, BA2 7AY, United Kingdom ${ }^{4}$ School of Chemistry, University of Nottingham, University Park NG7 2RD, United Kingdom ${ }^{5}$ Diamond Light Source, Rutherford Appleton Laboratory, Didcot, OX11 ODE, United Kingdom ${ }^{6}$ Chemistry, University of Southampton, Southampton, SO17 1BJ, UK.

${ }^{7}$ Central Laser Facility, Research Complex at Harwell, Rutherford Appleton Laboratory, Chilton, Oxfordshire OX11 0QX, United Kingdom

${ }^{8}$ X-ray Science Division, Argonne National Laboratory, Argonne, USA

${ }^{9}$ Department of Chemical and Environmental Engineering, University of Nottingham Ningbo China, 199 Taikang East Road, Ningbo 315100, China 


\section{Computational Details}

Density functional theory calculations were used to calculate minimum energy geometries and to simulate harmonic vibrational frequencies using the M06 exchange-correlation functional ${ }^{\mathrm{S1}}$ within the Q-Chem software package. ${ }^{\mathrm{S2}}$ Calculations were converged using the $6-311++G(d, p)$ basis set for $C, O$, $\mathrm{Si}, \mathrm{F}$, and $\mathrm{H}$ atoms, and the LANL08 pseudo-potential and basis set for $\mathrm{W}$ and Xe. ${ }^{\mathrm{S3}}$ The EML-(128,590) integration grid was used with this functional and detailed discussions of integration grids can be found elsewhere. ${ }^{54-56}$ Optimized geometries were confirmed by the absence of imaginary frequencies and the harmonic frequencies were scaled by a uniform factor of 0.96 to account for anharmonic effects. ${ }^{57}$

\section{Method of XAS Difference Data Fitting}

Using Feff software (Athena and Artemis) it is possible to derive EXAFS parameters from difference spectrum (such as Debye-Waller factors $\left[\sigma^{2}\right]$ and path lengths $[\Delta R]$ ) with a statistical validation.

This first requires a standard EXAFS fitting analysis of the ground state spectrum used to generate the difference spectrum. Then when perfoming the fitting analysis of the difference spectrum, the predetermined ground state parameters can be applied to the fit as a fixed parameters, where the amplitude factor is set to be equal to the negative of the difference data under analysis. Thus setting up equation (1) in the software.

This allows whole structures models of the photoexcited state/product to be input into the software in usual circumstances. When the difference data is fit, the software performs the difference subtraction in situ of the two models to give a statistical fit analysis of the difference spectrum:

$$
\Delta \chi=\chi \mathrm{L}_{\text {on }}-\chi \mathrm{L}_{\text {off }}
$$

Where $\Delta \mathrm{X}$ is the fitted difference data, $\mathrm{\chi} \mathrm{L}_{\text {on }}$ in the modelled photoexcited state/product, and $-\chi \mathrm{L}_{\text {off }}$ is the predetermined ground state. This follows a previously published article using a theortical basis to determine physical parameters using difference EXAFS data. ${ }^{58}[4]$

Thus by obtaing the best fit analysis of $\Delta \chi$ through refining the model of $\chi L_{o n}$, we can use the Artemis software to plot that model to provide a theoretical EXAFS spectrum of that complex, using the experimental difference data.

\section{- Amplitude reduction factor $-S_{0}^{2}$.}


Thus, the amplitude reduction factor of the laser off can be reasonably assumed to equal the negative of the laser on (on the assumption all reacted ground state forms the photoexcited state/product). Therefore, any unreacted $W(C O)_{6}$ is removed through the difference method, leaving only the photoactivated species minus the original $\mathrm{W}(\mathrm{CO})_{6}$ from which the photoproduct originated in the before laser spectrum. Therefore the resulting value of the $\mathrm{S}_{0}^{2}$ factor is a representation of the $\mathrm{W}(\mathrm{CO})_{6}$ conversion.

\section{Determination of the measure of the accuracy of fitting, R-factor}

The statistical fitting analysis follows the IFEFFET software and further detail is provided in the published literature. ${ }^{S 9}$ Essentially, a difference function, $f$, between the data and calculation is computed for each data point included in the evaluation of the fit, where the fit is derived from the sum of the pathways given by the EXAFS equation. The overall statistical verification of the fit as compared with the data is evaluated in the R-space, given by $R_{f a c} \cdot R_{f a c}$ is evaluated over all data points included in the fit (as defined by the R value given for each analysis).It is interpreted as a numerical evaluation of how closely the fitted function over plots the data. i.e. the smaller the $R_{\mathrm{fac}}$ the better the fit. As such it is a useful metric for judging accuracy of the data and the model. It does not define the physical viability of the individual parameters contributing to the fit and thus both $\mathrm{R}_{\mathrm{fac}}$ and all parameters contributing to that fit must be judged accordingly. The definition of the $R_{\mathrm{fac}}$ for the EXAFS analysis is:

$$
\begin{aligned}
& \mathrm{R}_{\mathrm{fac}}=\frac{\sum_{i=1}^{N}\left[f\left(R_{i}\right)\right]^{2}}{\sum_{i=1}^{N}\left(\left[\operatorname{Re}\left(\tilde{\chi}\left(R_{i} \mid \text { data }\right)\right)\right]^{2}+\left[\operatorname{Im}\left(\tilde{\chi}\left(R_{i} \mid \text { data }\right)\right)\right]^{2}\right)} \\
& \text { Where } f\left(R_{i}\right)=\operatorname{Re}\left[\tilde{\chi}\left(R_{i} \mid \text { data }\right)-\tilde{\chi}\left(R_{i} \mid \text { theory }\right)\right]+\operatorname{Im}\left[\tilde{\chi}\left(R_{i} \mid \text { data }\right)-\tilde{\chi}\left(R_{i} \mid \text { theory }\right)\right]
\end{aligned}
$$

Where $\mathrm{Re}=$ Real Fourier transform, Im = Imaginary Fourier transform,

$\tilde{\chi}=$ Fourier Transform EXAFS (determined by the $k$-range); $f=$ difference between the data and calculation for each data point included in the evaluation of the fit. 
For a fit evaluated in the R-space, the difference function includes the real and imaginary parts of the Fourier transformed data as given above by $f\left(R_{i}\right)$ (as such imaginary part and [Imaginary + real FT] are shown in each fitting analysis).

\section{XAS analysis, parameters and data.}
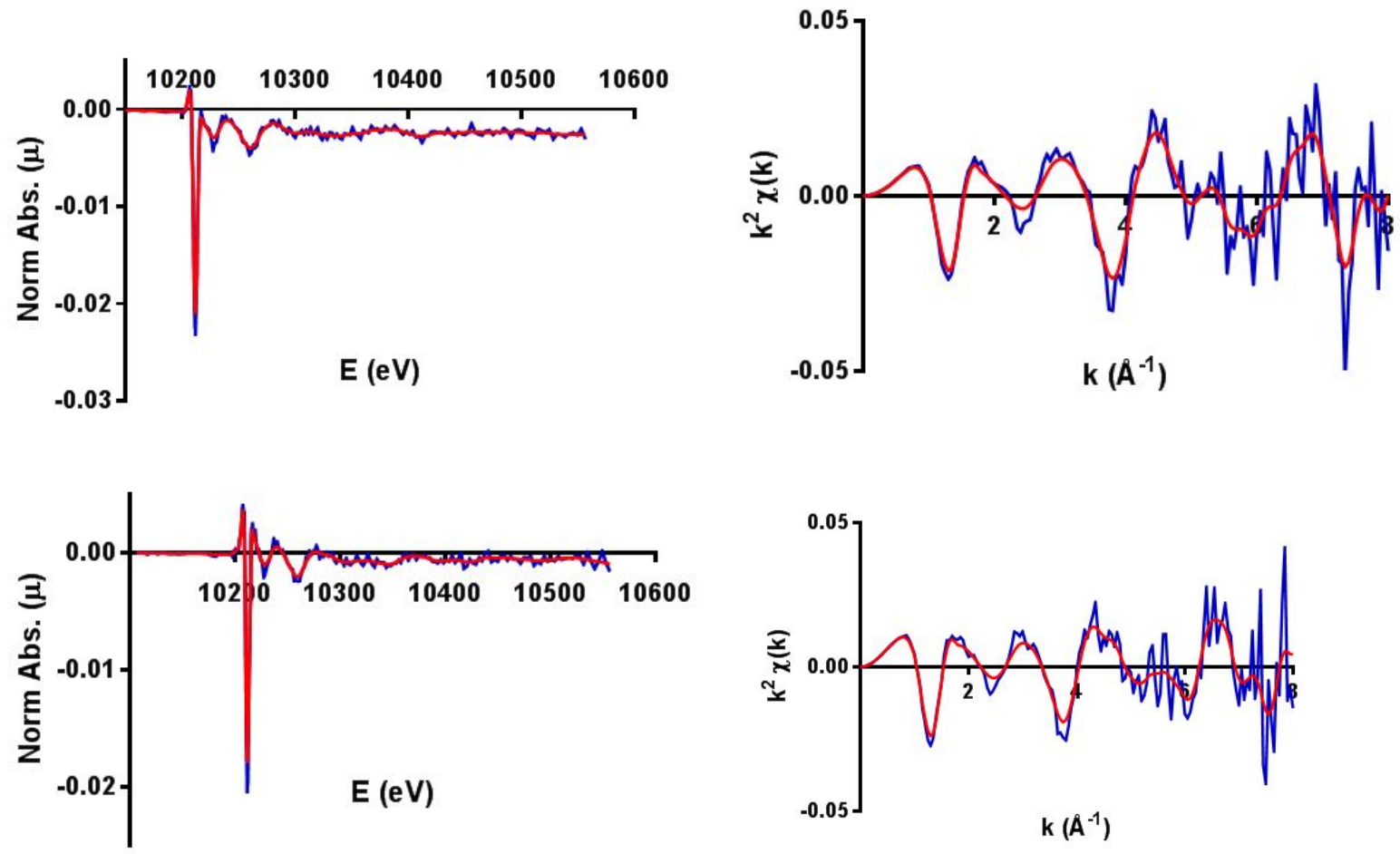

Figure S1 Displaying real and interpolative smoothed data (normalised absorption and EXAFS) of (Top) $\mathrm{W}(\mathrm{CO})_{6}+$ Heptane and (Bottom) $\mathrm{W}(\mathrm{CO})_{6}+\mathrm{HSiBu}_{3}$. Interpolation was used for the EXAFS analysis and for the linear combination analysis of the heptane-silane conversion.

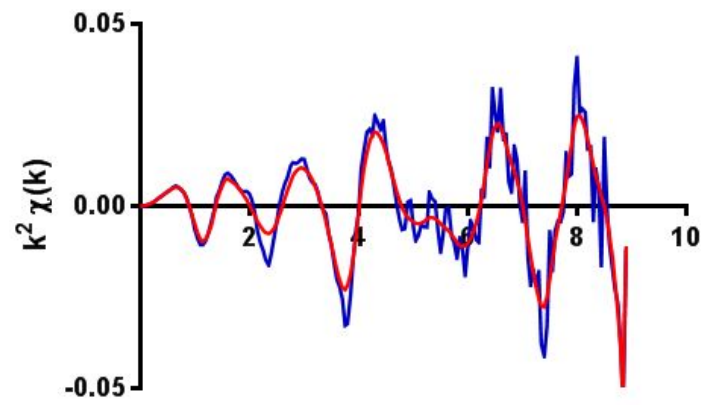

$k\left(A^{-1}\right)$

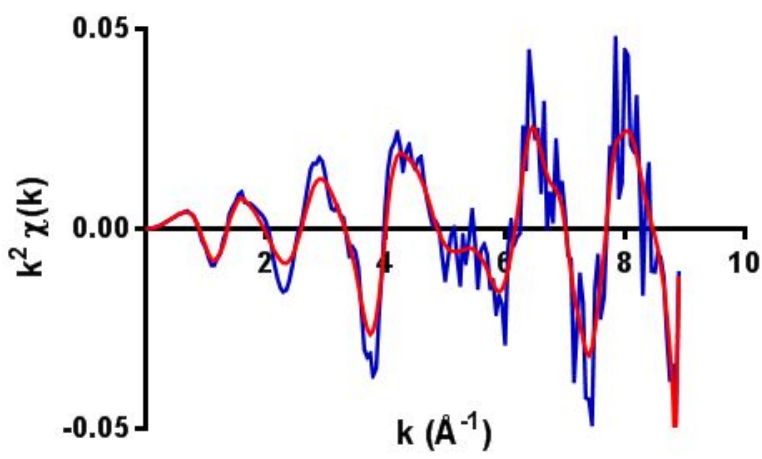

$k\left(A^{-1}\right)$

Figure S2 Displaying real and interpolative smoothed data EXAFS data of (Left) W(CO) ${ }_{6}+$ PFMCH under xenon and (right) $\mathrm{W}(\mathrm{CO})_{6}+$ PFMCH under xenon. 


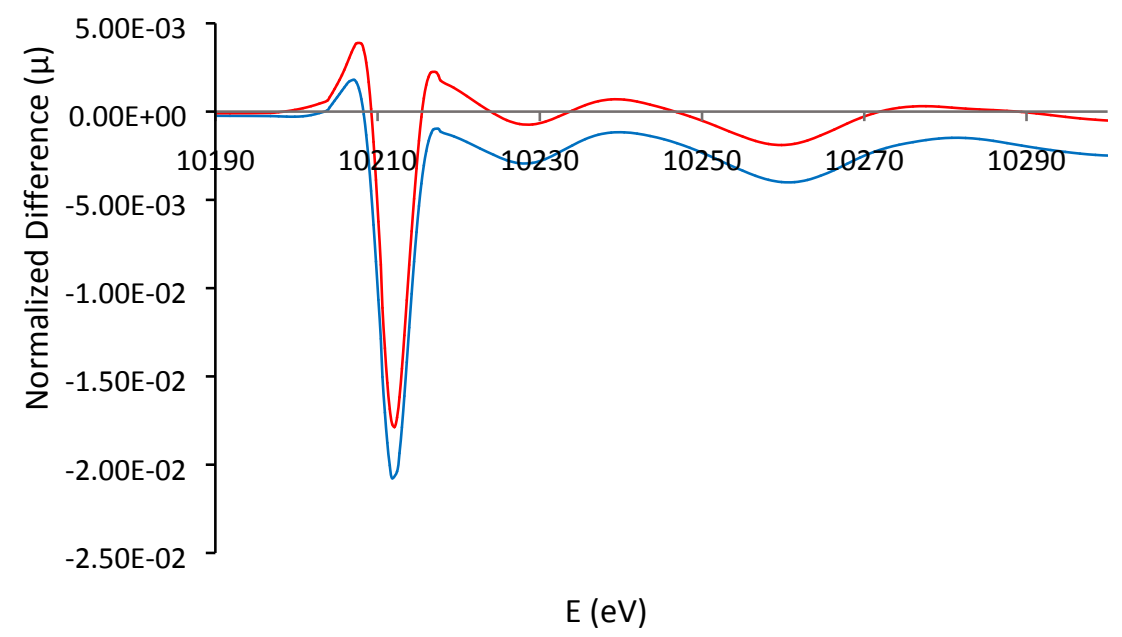

Figure S3 W $\mathrm{L}_{\text {III }}$ Edge XAS and difference spectra after $30 \mu \mathrm{s}$ of $\mathrm{W}(\mathrm{CO})_{6}$ + heptane (Blue) and doped $\mathrm{HSiBu}_{3}(\mathrm{Red})$.

Table S1 Distances and fitting parameters of $\left[\mathrm{W}(\mathrm{CO})_{5}(\right.$ heptane $\left.)\right]$ from the photolysis of $\mathrm{L}_{\text {III }}$ edge EXAFS of $\mathrm{W}(\mathrm{CO})_{6}$ in heptane over $30 \mu \mathrm{s}$ (MS = Multiple scattering).

\begin{tabular}{|l|l|l|}
\hline Paths (ligand) & Variable & $\begin{array}{l}\text { Fit determined R } \\
(\AA)\end{array}$ \\
\hline 1 trans W-C (CO) & $\Delta R=-0.02(1)$ & $1.94(1)$ (Trans) \\
4 cis W-C (CO) & $\sigma^{2}=0.007(1)$ & $2.03(1)$ (Cis) \\
\hline 1 W-C (heptane) & $\Delta R=-0.09(6)$ & $3.07(6)$ \\
& $\sigma^{2}=0.007(12)$ & \\
\hline
\end{tabular}

- Fixed Paths: $6 \mathrm{~W}-\mathrm{O}+\mathrm{W}-\mathrm{CO}(\mathrm{MS})$ at $3.13-3.21 \AA \sigma^{2}=0.002$.

- Laser off $\left[\mathrm{W}(\mathrm{CO})_{6}\right]$ - Fixed: $\mathrm{S}_{0}{ }^{2}=-0.0190, \mathrm{E}_{0}=11 \mathrm{eV}, 6 \mathrm{~W}-\mathrm{C}=2.07 \AA, 6 \mathrm{~W}-\mathrm{O}=3.22 \AA, 18 \mathrm{~W}$ $\mathrm{CO}(\mathrm{MS})=3.22 \AA, \sigma^{2}=0.001$ for all paths.

- Fit parameters: $\mathrm{S}_{0}^{2}=0.0190(1), \mathrm{E}_{0}=9 \mathrm{eV}, \mathrm{R}$-factor $=0.006, k$-range $=2-8 \AA^{-1}, k$-weighting $=2$; R-range $=1.35-3.5 \AA ̊$. Fitting window $=$ Hanning.

Table S2 Distances and fitting parameters of $\left[\mathrm{W}(\mathrm{CO})_{5}\left(\mathrm{HSiBu}_{3}\right)\right]$ from the photolysis of $\mathrm{L}_{\text {III }}$ edge EXAFS of $\mathrm{W}(\mathrm{CO})_{6}+\mathrm{HSiBu}_{3}$ in heptane over 50-75 $\mu \mathrm{s}$ (MS = Multiple scattering).

\begin{tabular}{|l|l|l|}
\hline Paths (ligand) & Variable & $\begin{array}{l}\text { Fit determined R } \\
(\AA)\end{array}$ \\
\hline 1 trans $\mathrm{W}-\mathrm{C}(\mathrm{CO})$ & $\Delta \mathrm{R}=0.01(1)$ & $2.01(1)$ (Trans) \\
4 cis $\mathrm{W}-\mathrm{C}(\mathrm{CO})$ & $\sigma^{2}=0.001(2)$ & $2.06(1)(\mathrm{Cis})$ \\
\hline $1 \mathrm{~W}-\mathrm{Si}\left(\mathrm{HSiBu}_{3}\right)$ & $\Delta \mathrm{R}=-0.00(3)$ & $3.20(3)$ \\
& $\sigma^{2}=0.001(8)$ & \\
\hline
\end{tabular}

- Fixed Paths: $6 \mathrm{~W}-\mathrm{O}+\mathrm{XW}-\mathrm{CO}(\mathrm{MS})$ at $3.18-3.23 \AA \sigma^{2}=0.002$. 
- Laser off $\left[\mathrm{W}(\mathrm{CO})_{6}\right]$ - Fixed: $\mathrm{S}_{0}^{2}=-0.03, \mathrm{E}_{0}=11 \mathrm{eV}, 6 \mathrm{~W}-\mathrm{C}=2.07 \AA, 6 \mathrm{~W}-\mathrm{O}=3.23 \AA$, $18 \mathrm{~W}$ $\mathrm{CO}(\mathrm{MS})=3.23, \sigma^{2}=0.001$ for all paths.

- Fit parameters: $\mathrm{S}_{0}^{2}=0.03(1), \mathrm{E}_{0}=9 \mathrm{eV}, \mathrm{R}$-factor $=0.024, k$-range $=3-8 \AA^{-1}, k$-weighting $=2,3$; R-range $=1.35-3.3 \AA$. Fitting window $=$ Hanning.

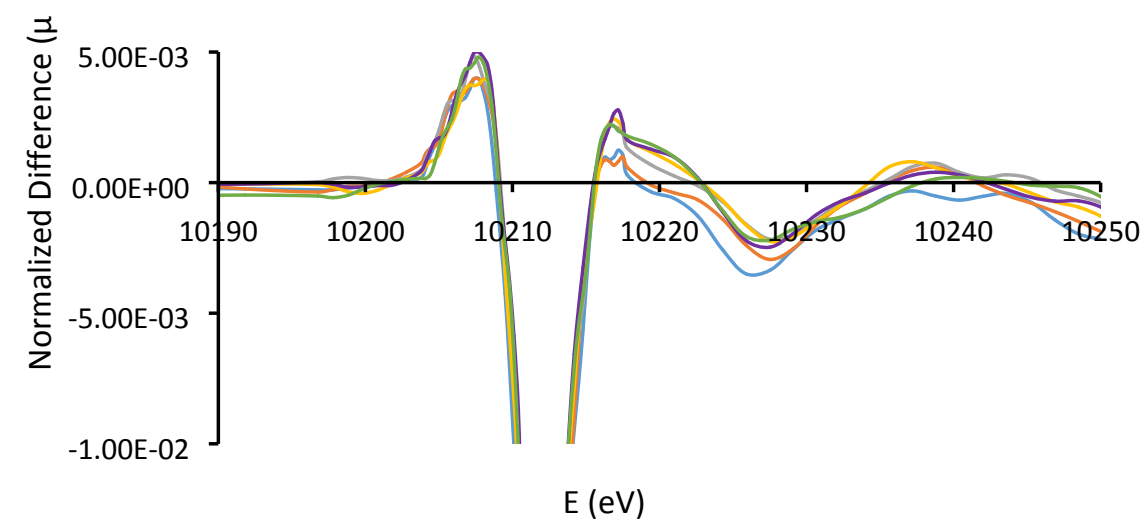

Figure S4 Difference spectra of the photolysis of $\mathrm{W}(\mathrm{CO})_{6}+\mathrm{HSiBu}_{3}$ at $266 \mathrm{~nm}$ in heptane over the first $12 \mu \mathrm{s}$ showing window of fitting analysis [blue $=0-2 \mu \mathrm{s}$; orange $=2-4 \mu \mathrm{s}$; grey $=4-6 \mu \mathrm{s}$; yellow $=6-8$ $\mu$; purple $=8-10 \mu \mathrm{s}$; green $=10-12 \mu \mathrm{s}]$.

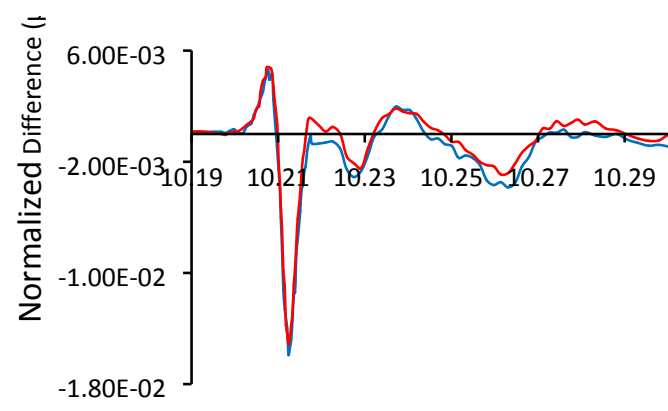

$\mathrm{E}(\mathrm{KeV})$

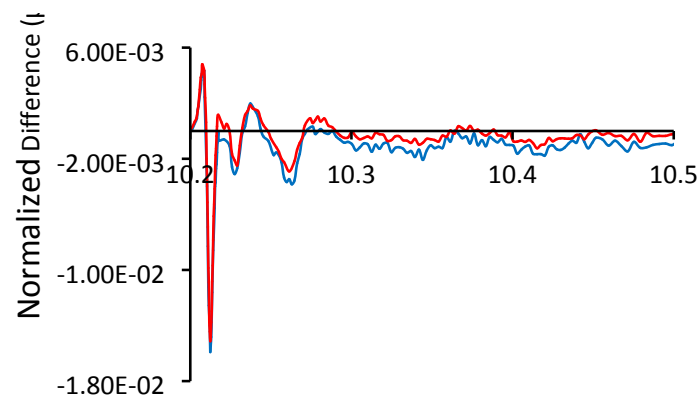

$\mathrm{E}(\mathrm{KeV})$

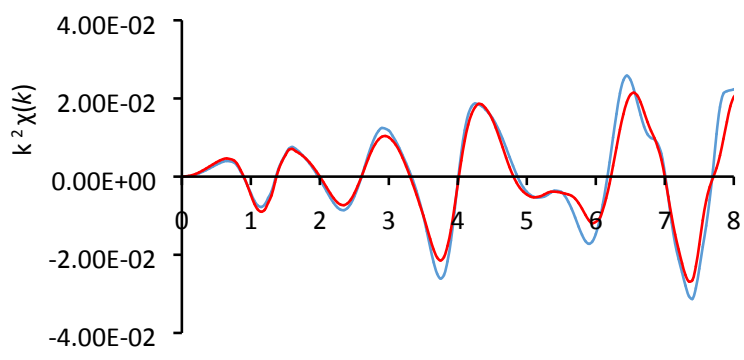

$k\left(\AA^{-1}\right)$

Figure $\mathbf{S} 5 \mathrm{~W} \mathrm{~L}_{\text {III }}$ Edge XAS and difference spectra after $4 \mu \mathrm{s}$, and extracted EXAFS after $8 \mu \mathrm{s}$ of $\mathrm{W}(\mathrm{CO})_{6}$ + PFMCH under helium (blue) and xenon (red).

Table S3 Distances and fitting parameters of $\left[\mathrm{W}(\mathrm{CO})_{5}(\mathrm{Xe})\right]$ from photolysis of $\mathrm{L}_{|| \mid}$edge EXAFS of $\mathrm{W}(\mathrm{CO})_{6}$ in PFMCH under xenon over the first $8 \mu$ s after laser flash (MS = Multiple scattering). 


\begin{tabular}{|l|l|l|}
\hline Paths (ligand) & Variable & $\begin{array}{l}\text { Fit determined R } \\
(\mathbf{A})\end{array}$ \\
\hline $\begin{array}{l}1 \text { trans } \mathrm{W}-\mathrm{C}(\mathrm{CO}) \\
4 \text { cis W-C (CO) }\end{array}$ & $\begin{array}{l}\Delta \mathrm{R}=0.003(6) \\
\sigma^{2}=0.001(1)\end{array}$ & $\begin{array}{l}1.96(1)(\text { Trans) } \\
2.06(1)(\text { Cis) }\end{array}$ \\
\hline $1 \mathrm{~W}-\mathrm{Xe}$ (xenon) & $\Delta \mathrm{R}=0.026(2)$ & $3.10(5)$ \\
& $\sigma^{2}=0.002(4)$ & \\
\hline 1 trans W-O & $\Delta \mathrm{R}=0.002(4)$ & $3.11(1)$ \\
4 cis W-O & $\sigma^{2}=0.001(1)$ & $3.20(1)$ \\
$31 \mathrm{~W}-\mathrm{CO}(\mathrm{MS})$ & & $3.11(1)-3.52(1)$ \\
\hline
\end{tabular}

- Laser off $\left[\mathrm{W}(\mathrm{CO})_{6}\right]$ - Fixed: $\mathrm{S}_{0}^{2}=-0.065, \mathrm{E}_{0}=11 \mathrm{eV}, 6 \mathrm{~W}-\mathrm{C}=2.08 \AA, 6 \mathrm{~W}-\mathrm{O}=3.21 \AA$, $42 \mathrm{~W}$ $\mathrm{CO}(\mathrm{MS})=3.21-3.56 \AA, \sigma^{2}=0.001$ for all paths.

- Fit parameters: $\mathrm{S}_{0}{ }^{2}=0.065(\mathrm{Fix}), \mathrm{E}_{0}=7.8(\mathrm{Fix}) \mathrm{eV}, \mathrm{R}$-factor $=0.003, k$-range $=3.5-8.2 \AA^{-1}, k$ weighting $=3 ;$ R-range $=1.6-3.8 \AA$. Fitting in $\mathrm{R}$ window $=$ Hanning.

Table S4 Distances and fitting parameters of $\left[\mathrm{W}(\mathrm{CO})_{5}(\mathrm{PFMCH})\right]$ from $\mathrm{L}_{\text {III }}$ edge EXAFS of $\mathrm{W}(\mathrm{CO})_{6}$ in $\mathrm{PFMCH}$ under helium over the first $8 \mu \mathrm{s}$ after laser flash (MS = Multiple scattering).

\begin{tabular}{|l|l|l|}
\hline Paths & Variable & $\begin{array}{l}\text { Fit determined } \mathbf{R} \\
(\AA \AA)\end{array}$ \\
\hline 1 trans W-C (CO) & $\Delta R=-0.05(1)$ & $1.97(1)($ Trans) \\
4 cis W-C (CO) & $\sigma^{2}=0.006(2)$ & $2.05(1)($ Cis $)$ \\
\hline $1 \mathrm{~W}-\mathrm{F}$ & $\Delta \mathrm{R}=0.07(6)$ & $2.65(6)$ \\
& $\sigma^{2}=0.013(10)$ & \\
\hline
\end{tabular}

- Fixed Paths: $5 \mathrm{~W}-\mathrm{O}$ at $3.12-3.19 \AA, \sigma^{2}=0.001 ; 34 \mathrm{~W}-\mathrm{CO}(\mathrm{MS}) 3.12-3.57 \AA, \sigma^{2}=0.001 ; 27$ $\mathrm{W}-\mathrm{CO}$ (MS) at $3.98-4.77 \AA, \sigma^{2}=0.008$.

- Laser off $\left[\mathrm{W}(\mathrm{CO})_{6}\right]$ - Fixed: $\mathrm{W}(\mathrm{CO})_{6}: \mathrm{S}_{0}^{2}=-0.03, \mathrm{E}_{0}=11 \mathrm{eV}, 6 \mathrm{~W}-\mathrm{C}=2.08 \AA, 6 \mathrm{~W}-0=3.21 \AA$, $300 \mathrm{~W}-\mathrm{CO}(\mathrm{MS})=3.21-5.04 \AA$, $\sigma^{2}=0.001$ for all paths.

- Fit parameters: $\mathrm{S}_{0}^{2}=0.03(1), \mathrm{E}_{0}=6.6 \mathrm{eV}, \mathrm{R}$-factor $=0.017, k$-range $=3-8 \AA^{-1}, k$-weighting $=$ $1,2,3 ;$ R-range $=1.6-4.5 \AA$. Fitting window $=$ Hanning.
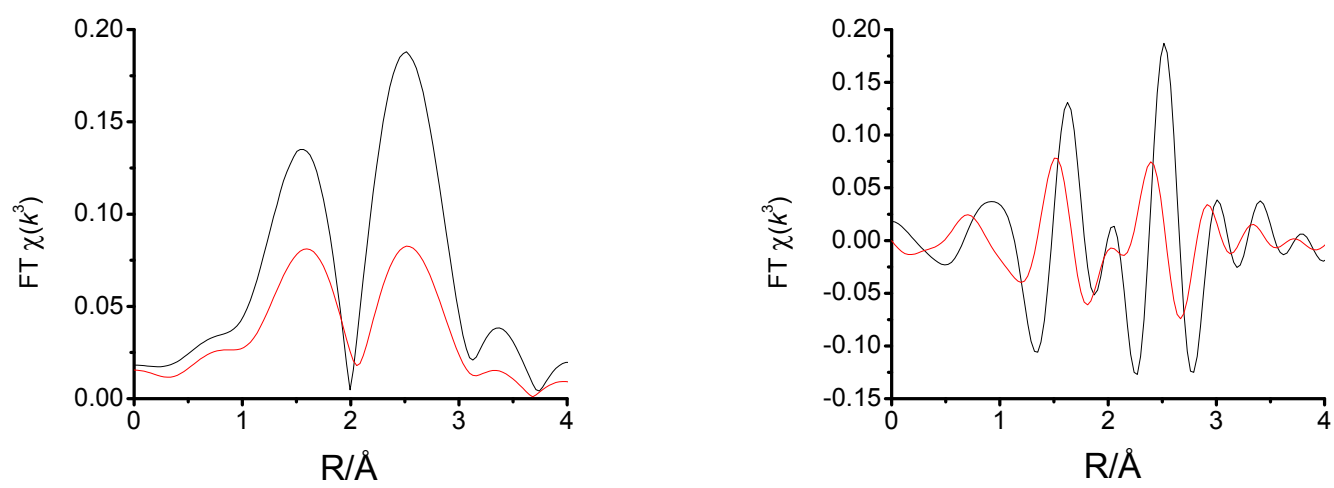

Fig. S6 Comparsion of the Fourier transform of the two optimised models of $W(\mathrm{CO}) 5 \mathrm{Xe}$ (Blue) and $\mathrm{W}(\mathrm{CO}) 5(\mathrm{PFMCH}$ ) (Red) as defined by the EXAFS fitting analyses ( $\mathrm{k} 3$ weighting for k-range $3-8 \AA-1$ ). 


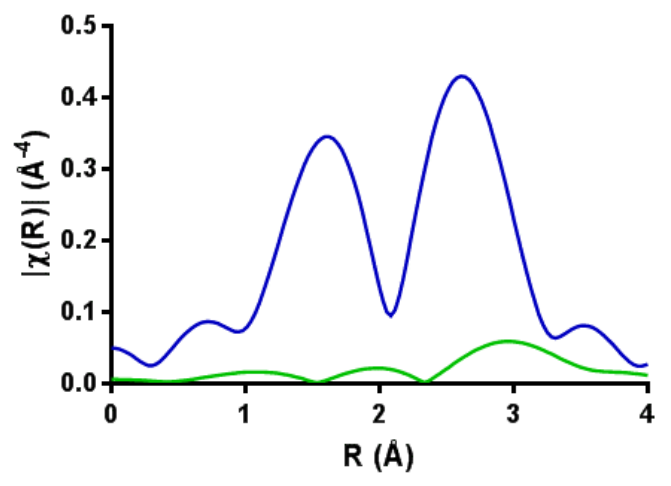

Fig. S7 Displaying the Fourier transform of the derived model from the EXAFS fitting analysis of $\mathrm{W}(\mathrm{CO})_{5} \mathrm{Xe}$ (blue) with $\mathrm{W}$-Xe path contribution (green) (k-range 3.5-8.2, in k-weighting 3).
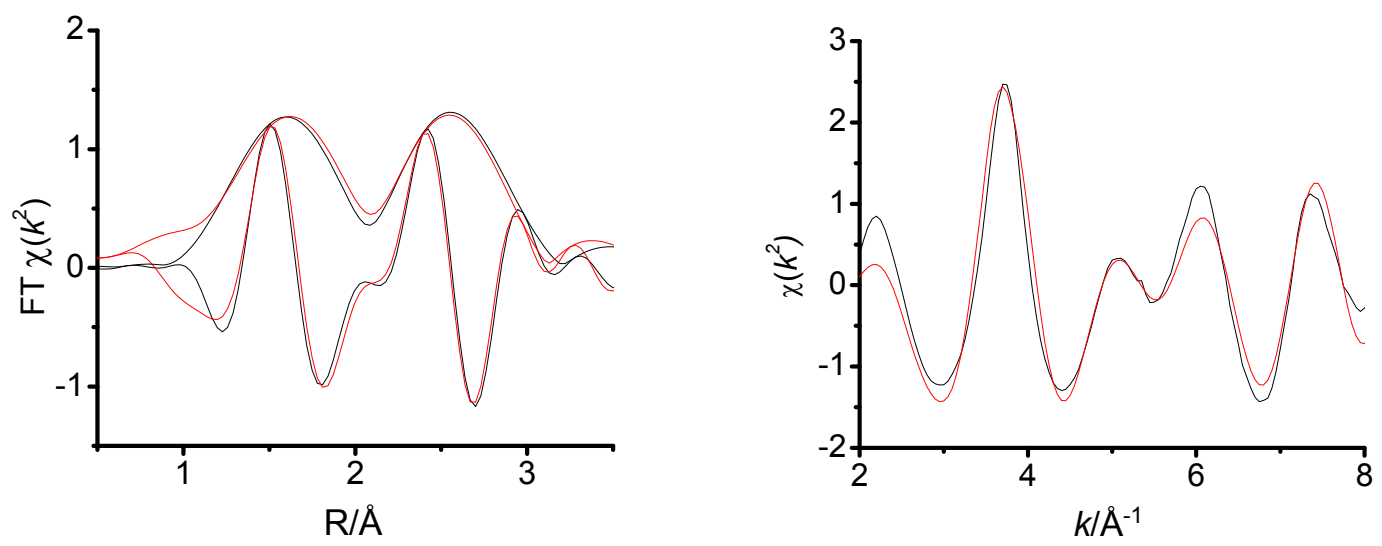

Fig. $\mathbf{S 8}$ Displaying the $W L_{|| 1}$ edge EXAFS analysis of before laser/ground state spectrum of $W(C O)_{6}$ in heptane, with the EXAFS data (Black) and fit analysis (Red). W(CO) $)_{6}: \mathrm{S}_{0}{ }^{2}=0.86, \mathrm{E}_{0}=11(2) \mathrm{eV}, 6 \mathrm{~W}-\mathrm{C}=$ $2.07(2) \AA ; 6 \mathrm{~W}-\mathrm{O}=3.21(2) \AA, 300 \mathrm{~W}-\mathrm{CO}(\mathrm{MS})=3.21-5.04 \AA, \sigma^{2}=0.001$ for all paths.

\section{References}

[S1] Zhao, Y.; Truhlar, D. G. The M06 suite of density functionals for main group thermochemistry, thermochemical kinetics, noncovalent interactions, excited states, and transition elements: two new functionals and systematic testing of four M06-class functionals and 12 other functionals Theor. Chem. Acc. 2008, 120, 215.

[S2] Shao, Y. H.; Gan, Z. T.; Epifanovsky, E.; Gilbert, A. T. B.; Wormit, M.; Kussmann, J.; Lange, A. W.; Behn, A.; Deng, J.; Feng, X. T.; Ghosh, D.; Goldey, M.; Horn, P. R.; Jacobson, L. D.; Kaliman, I.; Khaliullin, R. Z.; Kus, T.; Landau, A.; Liu, J.; Proynov, E. I.; Rhee, Y. M.; Richard, R. M.; Rohrdanz, M. A.; Steele, R. P.; Sundstrom, E. J.; Woodcock, H. L.; Zimmerman, P. M.; Zuev, D.; Albrecht, B.; Alguire, E.; Austin, B.; Beran, G. J. O.; Bernard, Y. A.; Berquist, E.; Brandhorst, K.; Bravaya, K. B.; Brown, S. T.; Casanova, D.; Chang, C. M.; Chen, Y. Q.; Chien, S. H.; Closser, K. D.; Crittenden, D. L.; Diedenhofen, M.; DiStasio, R. A.; Do, H.; Dutoi, A. D.; Edgar, R. G.; Fatehi, S.; Fusti-Molnar, L.; Ghysels, A.; Golubeva-Zadorozhnaya, A.; Gomes, J.; Hanson-Heine, M. W. D.; Harbach, P. H. P.; Hauser, A. W.; Hohenstein, E. G.; Holden, Z. C.; Jagau, T. C.; Ji, H. J.; Kaduk, B.; Khistyaev, K.; Kim, J.; Kim, J.; King, R. A.; Klunzinger, P.; Kosenkov, D.; Kowalczyk, T.; Krauter, C. M.; Lao, K. U.; Laurent, A. D.; Lawler, K. V.; Levchenko, S. V.; Lin, C. Y.; Liu, F.; Livshits, E.; Lochan, R. C.; Luenser, A.; Manohar, P.; Manzer, S. F.; Mao, S. P.; Mardirossian, N.; 
Marenich, A. V.; Maurer, S. A.; Mayhall, N. J.; Neuscamman, E.; Oana, C. M.; Olivares-Amaya, R.; O'Neill, D. P.; Parkhill, J. A.; Perrine, T. M.; Peverati, R.; Prociuk, A.; Rehn, D. R.; Rosta, E.; Russ, N. J.; Sharada, S. M.; Sharma, S.; Small, D. W.; Sodt, A. Advances in molecular quantum chemistry contained in the Q-Chem 4 program package Mol. Phys. 2015, 113, 184.

[S3] Roy, L. E.; Hay, P. J.; Martin, R. L. Revised basis sets for the LANL effective core potentials J. Chem. Theory Comput. 2008, 4, 1029.

[S4] Chien, S. H.; Gill, P. M. W. SG-0: A small standard grid for DFT quadrature on large systems J. Comput. Chem. 2006, 27, 730.

[S5] Gill, P. M. W.; Johnson, B. G.; Pople, J. A. A standard grid for density-functional calculations Chem. Phys. Lett. 1993, 209, 506.

[S6] Boese, A. D.; Klopper, W.; Martin, J. M. L. Anharmonic force fields and thermodynamic functions using density functional theory Mol. Phys. 2005, 103, 863.

[S7] Merrick, J. P.; Moran, D.; Radom, L. An evaluation of harmonic vibrational frequency scale factors $J$. Phys. Chem. A 2007, 111, 11683.

[S8] König, C. F. J.; van Bokhoven, J. A.; Schildhauer, T. J.; Nachtegaal, M. Quantitative Analysis of Modulated Excitation X-ray Absorption Spectra: Enhanced Precision of EXAFS FittingJ. Phys. Chem. C, 2012, 116, 19857.

[S9] Ravel, B. "Quantitative EXAFS analysis," in X-Ray Absorption and X-Ray Emission Spectroscopy: Theory and Applications, edited by J. A. van Bokhoven and C. Lamberti (John Wiley \& Sons, Ltd., Chichester, UK, 2016), pp. 281-302. 